\title{
Contrasting anti-predation responses in the intertidal periwinkle Littorina sitkana: effects of chemical cue, body size and time of day
}

\author{
HisAe OJima \& SATOSHI WADA* \\ Laboratory of Marine Biology, Graduate School of Fisheries Science, Hokkaido University, 3-1-1 Minato-cho, Hakodate 041- \\ 8611, Japan
}

Received 24 August 2012; Accepted 11 February 2013

\begin{abstract}
Some animals show multiple behavioral responses after detection of chemical cues indicating a predation threat. Individuals of the high intertidal periwinkle, Littorina sitkana, showed two contrasting anti-predation responses, immobile cautiousness and active fleeing, against the predatory crab, Hemigrapsus sanguineus. This study examined the combined effects of chemical cues of predation threat (crab, crushed conspecific, mixed crab and crushed conspecific, and control), body size, and time (morning, mid-day and late-evening) on the anti-predation behaviors of L. sitkana. The cautious response of L. sitkana was strongest under the crab treatment, with the earliest fleeing response appearing when presented with the mixed chemical cue of crabs and crushed conspecifics. Time of day also affected the anti-predation responses, with a longer cautious response during late-evening than mid-day under control conditions, and no significant difference between late-evening and mid-day in response to the three types of chemical cues of predation threat. The fleeing response occurred more rapidly during late-evening than midday for the four types of chemical conditions; there was no significant difference between morning and mid-day under the control condition; and it occurred more rapidly during morning than mid-day under the three predation threat conditions. Larger individuals showed longer cautious responses for all conditions and remained submerged in seawater for longer under the three predation threat conditions. It is suggested that the level of predation risk may be assessed by L. sitkana and used to elicit the appropriate of the two contrasting anti-predation responses.
\end{abstract}

Key words: anti-predatory response, chemical cue, Littorina, periwinkle

\section{Introduction}

Animals may protect themselves from predators in various ways. Anti-predation strategies include morphological structures (Lively 1986, Kishida et al. 2006, Vaughn 2010), life history characters (Crowl \& Covich 1990, Behrens Yamada et al. 1998) and behaviors (Hazlett \& McLay 2000, Mima et al. 2003, Gristina et al. 2011), the latter being the most pervasive response against predators in animals (reviewed by Lima \& Dill 1990). Anti-predation behavior is associated with energetic costs (Martín \& Lopez 2000, Martín et al. 2005, Iwami et al. 2007) and opportunity costs that are related to other behaviors such as foraging and mating (Reaney 2007, Selden et al. 2009), so intuitively it is expected that animals adjust their behavioral re-

\footnotetext{
*Corresponding author: S. Wada; E-mail,wadas@fish.hokudai.ac.jp
}

sponses according to the level of predation risk and various external and internal factors related to the costs (Lima \& Dill 1990, Mathis \& Hoback 1997, Wellborn 2002).

Animals in aquatic environments typically detect potential predators by chemical cues released from the predator (Chivers et al. 1996, Mima et al. 2003) and/or damaged conspecifics (Hazlett 1994, Higuchi et al. 2004). Some species show multiple behavioral responses in detecting chemical cues (Lehtiniemi 2005, Wasson \& Lyon 2005, Mach \& Bourdeau 2011). A freshwater snail, Physella gyrina, has been shown to differentiate between cues from two different predators, crayfish and pumpkinseed fish (Turner et al. 1999): hiding under cover in the presence of fish; and moving to the water surface in the presence of crayfish. Ichinose (2002) reported that, in response to an extract of conspecifics, small Pomacea canaliculata (freshwater periwinkles) crawl out of the water and (under the 
same conditions) large individuals bury themselves in the substrate. The body size and sex of porcelain crabs affect the decision to perform two mutually exclusive tactics against predators: fleeing and fighting (Wasson \& Lyon 2005). These flexible anti-predator behaviors suggest that many aquatic invertebrates somehow assess the immediate predation risk in order to select the most appropriate response.

Aquatic animals show distinct activity rhythms entrained by the physical environment, including the diurnal light cycle, tidal rhythms and temperature. For example, many crabs and sea urchins have a nocturnal activity rhythm and are less active during daylight (see, for example, Skajaa et al. 1998, Yoshimura \& Motokawa 2010). Since predation and the efficacy of anti-predation behaviors are considered to vary with the physical environment, the environmental rhythms of potential prey animals affect predation risk (Jacobsen \& Stabell 1999, Sakamoto et al. 2006). However, few studies have investigated the effects of environmental rhythms on anti-predator responses.

The present study investigates the combined effects of chemical cues of predation threat, body size and time of day on the anti-predator behaviors of the intertidal periwinkle, Littorina sitkana. This species is a herbivorous gastropod commonly found in sheltered locations high in the intertidal zone. Although high densities of L. sitkana are found in tidal pools in some study sites (Jones \& Boulding 1999), there is a difference in intertidal distribution among populations: Behrens Yamada et al. (1998) compared three populations of $L$. sitkana and found that the one with the highest predation risk has the highest intertidal distribution. When L. sitkana individuals from the high intertidal zone were transferred to the low intertidal zone, they displayed a strong and consistent tendency to move shoreward (Rochette \& Dill 2000). This species has been shown to respond to chemical cues indicating predation threat (Behrens Yamada et al. 1998), and a difference in escape behavior between populations has also been observed: upward migration of individuals from rocky shores; and hiding in crevices by individuals on a mud flat (Behrens Yamada et al. 1989). In preliminary observations in the present study, L. sitkana individuals collected from the study site showed two contrasting anti-predation responses against the shore crab, Hemigrapsus sanguineus: immobile cautiousness and active fleeing.. Hemigrapsus is a common nocturnal predator on periwinkles along rocky shores in northern Japan.

\section{Materials and Methods}

The study was conducted between 7 and 11 August 2006. Individuals of the periwinkle $L$. sitkana (6.3$16.3 \mathrm{~mm}$ in shell length) and the sympatric predatory shore crab, $H$. sanguineus, were collected from the intertidal zone in Usujiri, Minami-Kayabe, on the Pacific rocky coast of south Hokkaido, northern Japan $\left(41^{\circ} 57 \mathrm{~N}\right.$, $\left.140^{\circ} 58 \mathrm{E}\right)$. All periwinkles were out of water when collected. Prior to each experiment, individual periwinkles were kept in plastic tanks $(56 \times 39 \mathrm{~cm}, \times 21 \mathrm{~cm}$ high $)$ with running natural seawater for 12 to 24 hours under ambient temperature and a natural light cycle. They were not fed during this period, and most remained above the waterline in the tanks.

Experimental seawater with chemical cues was produced using the following procedures about three hours before each of the trials. Predator cue water was prepared by placing five $H$. sanguineus into three liters of seawater (crab treatment). Crushed conspecific cue water consisted of mixing five crushed $L$. sitkana into 31 seawater (conspecific treatment). Mixed cue water was composed of five $H$. sanguineus and five crushed L. sitkana in 31 seawater (within which the H. sanguineus always vigorously ate the crushed L. sitkana). Preliminary trials showed that these cue concentrations were sufficient to initiate responses in L. sitkana. Control water was natural seawater without additional chemical cues.

Behavioral trials were carried out using the same procedure for all experiments under laboratory conditions analogous to those in which the periwinkles were maintained, using small plastic containers $(10 \times 14 \mathrm{~cm}, \times 5 \mathrm{~cm}$ high $)$ on the underneath of which a circle of $2 \mathrm{~cm}$ diameter was drawn. At the start of each trial, $150 \mathrm{ml}$ of one of the cue solutions, or control water, was introduced to each container (corresponding to a depth of $1.07 \mathrm{~cm}$ ). For each trial, a periwinkle was placed within the circle marked on the container, and its behavior was observed for ten minutes. During preliminary observations, L. sitkana showed two contrasting behavioral responses to the chemical cues: (1) a cautious response, in which they moved very slowly and stayed within the circle, not withdrawing inside the shell; and (2) a fleeing response in which they moved quickly out of the circle to the edge of the container and climbed up above the waterline.

The duration of the cautious response was defined as the period from the start of the trial to when the periwinkle moved outside the circle. The fleeing response was defined as the period between the end of the cautious response and when the individual climbed vertically above the waterline of the container, which marked the end of the trial. Trials were also ended if after a total of $10 \mathrm{~min}$. the periwinkle remained within the circle and/or under the water surface. The shell length of each periwinkle was measured with calipers to the nearest $0.05 \mathrm{~mm}$. Three trials were conducted at three times each day (i.e. morning, 7:30-9:30; mid-day, 11:45-13:45; and late-evening, 20:45-22:45), from mid-day on 7 August to the morning of 11 August 2006. A series of trials at each time was conducted for all treatments, using 15 periwinkles for each treatment combination at each time per day, for a total of 720 individuals.

Since observations often ended before observing either of the two behavioral responses (i.e., cautious response and/or fleeing response), the experiment produced cen- 
sored data which were therefore analyzed with Cox's proportional hazards model, by assuming that there was a baseline hazard function at which periwinkles showed each response, with shell length as a covariate, under the control condition at mid-day. Experiments were conducted over $4 \mathrm{~d}$, so some environmental conditions (such as temperature, light intensity and tidal level in the field) differed among the four days, and therefore the date was treated as a stratification variable in the model. The initial, full (most complex) model included the three explanatory factors (chemical treatment, shell length and time) and all possible interactions among these factors to explain each of the two responses. The best model was then selected from all possible models, to examine how and which factors and/or their interaction terms explained the occurrence of each anti-predation response. Model selection was based on Akaike's Information Criterion (AIC) values wherein models with the lowest AIC values were considered the most parsimonious. Statistics were calculated using the program $\mathrm{R}$ ver. 2.14.1 (R Development Core Team, 2011).

\section{Results}

\section{Cautious response}

The Cox's proportional hazards model with the lowest AIC value for the cautious response included three explanatory factors and the interaction term between chemical treatment and time (Table 1). Crab and mixed chemical cues clearly affected the cautious response in L. sitkana (Fig. 1, Table 2). The lowest coefficient $(\beta=-1.699 \pm$ $0.205 \mathrm{SE}$ ) was recorded in the crab treatment (Table 2), indicating that this produced the strongest cautious response (Fig. 1). The coefficient for mixed treatment ( $\beta=-0.659 \pm$ 0.186 ) was relatively small as an absolute value in comparison with the crab treatment. Responses to the crushed conspecific treatment did not differ from those to the control treatment (Fig. 1).

The interaction term between the chemical treatment and time was included in the best model and the coefficients were statistically significant (Crab: Late-evening and Mixed: Late-evening in Table 2). The effect of time, with shell length as a covariate, on the cautious response for each treatment was analyzed (Fig. 2, Table 3) to interpret how the treatment variable interacted with time. While periwinkles moved out of the circle rapidly during the morning and at mid-day under the control treatment, the timing was significantly slower during late-evening (Fig. 2a, Table 3a). However, no significant differences between late-evening and mid-day were found among the three experimental treatments (Fig. 2b-d, Table 3b-d). Although individuals under the crab treatment in general started to move later than in the control treatment ( $\beta=-1.699 \pm 0.205$; Fig. 1, Table 2 ), they moved out of the circle relatively rapidly during late-evening in comparison with the control treatment $(\beta=0.262 \pm 0.207$; Fig. $2 b$, Table $3 b)$. While a clear difference in the duration of the cautious response was found between late-evening and mid-day under the control treatment ( $\beta=0.479 \pm 0.196$; Fig. 2a, Table $3 a)$, the duration of the cautious response in late-evening was similar to that at mid-day under the mixed condition ( $\beta=-0.094 \pm 0.188$; Fig. $2 d$, Table $3 d$ ). Body size also affected the cautious response which was consistently longer for larger individuals (Tables 2-3).

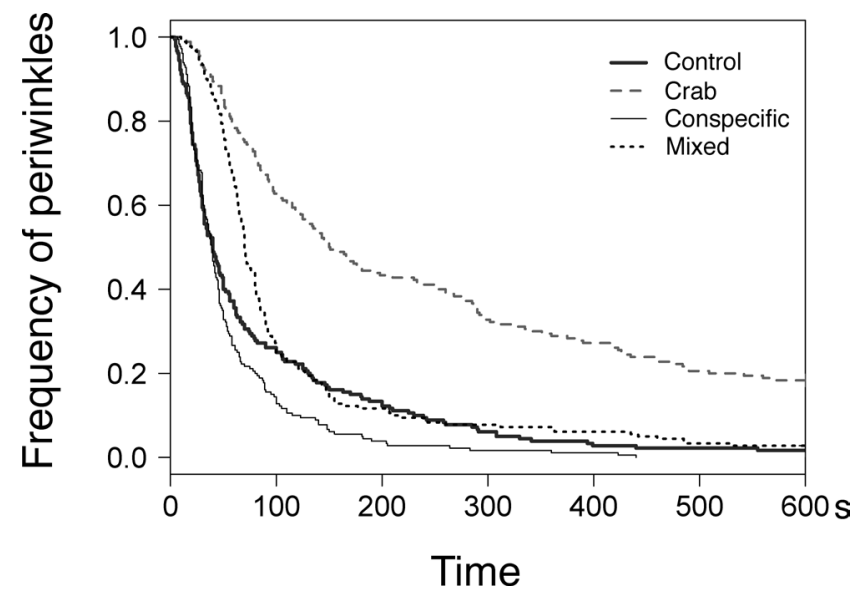

Fig. 1. Comparison of the proportion of Littorina sitkana individuals showing the cautious response for the four chemical cue sources representing different types of predation risk.

Table 1. Model selection table for cautious response in Littorina sitkana.

\begin{tabular}{cccccccccc}
\hline Rank & $\begin{array}{c}\text { A) } \\
\text { Treatment }\end{array}$ & $\begin{array}{c}\text { B) Time } \\
\text { phase }\end{array}$ & $\begin{array}{c}\text { C) } \log _{10} \\
\text { (Shell length) }\end{array}$ & $\begin{array}{c}\text { Strat } \\
\text { (Date) }\end{array}$ & A : B & A : C & B : C & AIC & $\Delta$ AIC \\
\hline 1 & + & + & -1.840 & + & + & - & - & 5684.3 \\
2 & + & + & -1.719 & + & + & + & - & 5686.6 & 2.26 \\
3 & + & + & -2.129 & + & + & - & + & 5687.3 \\
4 & + & + & -1.824 & + & - & - & - & 5689.1 \\
5 & + & - & -1.830 & + & - & - & - & 5689.4 \\
\hline
\end{tabular}

The best five models are ranked on the basis of AIC. All '+' and numerical values are included in the model; -, excluded from the model. The best model therefore include factors A, B, C and the interaction between A and B (A : B). Since it took four days to conduct the experiment, the date was treated as a stratification variable 'strata (Date).' $\triangle \mathrm{AIC}$ is the difference in AIC between the best model and each model. 


\section{Fleeing response}

The Cox's proportional hazards model with the lowest AIC value for the fleeing response included three explanatory variables and an interaction term between treatment and time of day (Table 4). Although the terms of the best model for the fleeing response were the same as those for the cautious response, the relative values of the coefficient for each variable were different between the two models. Crab and mixed treatments showed shorter times of exiting above the waterline than for the control treatment (Fig. 3, Table 5); and periwinkles under the mixed treatment

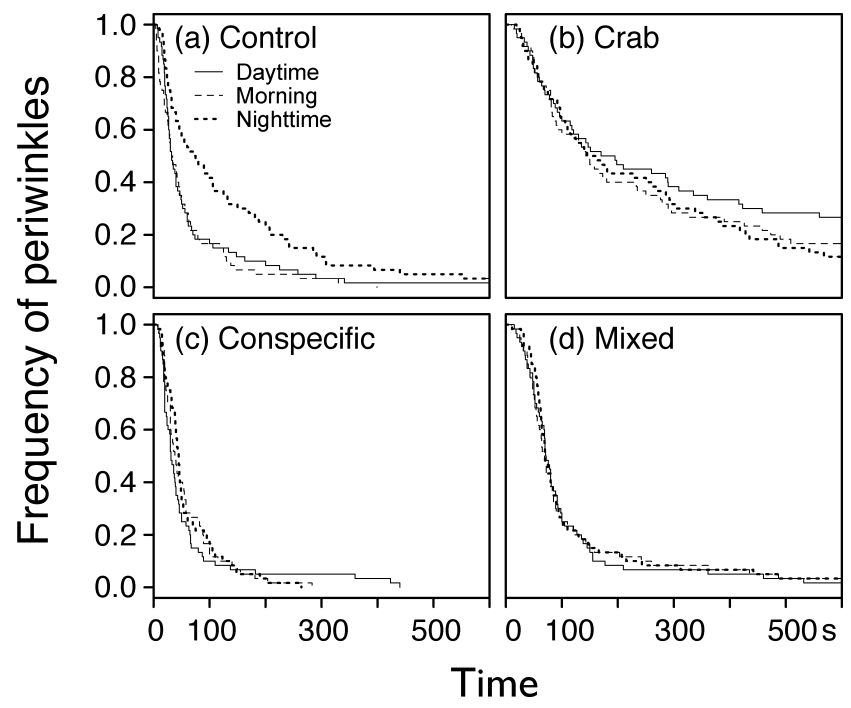

Fig. 2. Comparison of the proportion of Littorina sitkana individuals showing the cautious response for each of four types of chemical cue at three different times of day. moved above the waterline more rapidly than those under the control treatment $(\beta=2.634 \pm 0.322$; Fig. 3$)$. In contrast to the cautious response, the coefficient for crab treatment ( $\beta=1.284 \pm 0.358)$ was relatively small as an absolute value in comparison with the mixed treatment (Table 5).

The interaction term between the chemical treatment and time of day was included in the best model (Table 4). The effect of time of day, with shell length as a covariate, on the fleeing response for each treatment (Fig. 4, Table 6) was analyzed to detect the difference between the control treatment and the three experimental treatments, focusing on the effect of time of day on the occurrence of the fleeing response. While the fleeing response occurred more rap-

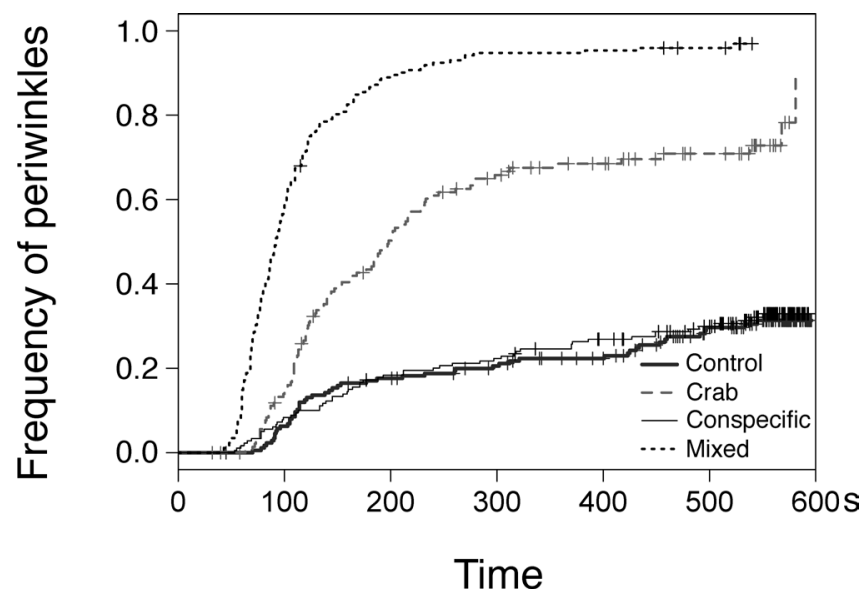

Fig. 3. Comparison of the proportion of Littorina sitkana individuals showing the fleeing response for the four chemical cue sources representing different types of predation risk. (Crosses $(+)$ indicate censored data: response incomplete within $10 \mathrm{~min}$.).

Table 2. Results of the best model to explain the cautious response behavior of the periwinkle, Littorina sitkana, in which Cox's proportional hazard model was applied.

\begin{tabular}{|c|c|c|c|c|c|}
\hline Explanatory factor & Coefficient $(\beta)$ & $\exp (\beta)$ & $\operatorname{SE}(\beta)$ & $Z$ & $P$ \\
\hline \multicolumn{6}{|l|}{ Treatment } \\
\hline Crab & -1.699 & 0.183 & 0.205 & -8.300 & $<0.001$ \\
\hline Conspecific & 0.237 & 1.268 & 0.185 & 1.280 & 0.200 \\
\hline Mixed & -0.659 & 0.517 & 0.186 & -3.535 & $<0.001$ \\
\hline $\log$ (Shell length) & -1.840 & 0.159 & 0.230 & -7.992 & $<0.001$ \\
\hline \multicolumn{6}{|l|}{ Time phase } \\
\hline Morning & 0.006 & 1.006 & 0.187 & 0.031 & 0.975 \\
\hline Nighttime & -0.640 & 0.527 & 0.188 & -3.395 & $<0.001$ \\
\hline \multicolumn{6}{|l|}{ Treatment: Time phase } \\
\hline Crab: Morning & 0.086 & 1.090 & 0.279 & 0.309 & 0.757 \\
\hline Conspecific: Morning & -0.255 & 0.775 & 0.264 & -0.964 & 0.335 \\
\hline Mixed: Morning & -0.156 & 0.856 & 0.262 & -0.594 & 0.552 \\
\hline Crab: Nighttime & 0.909 & 2.483 & 0.278 & 3.266 & 0.001 \\
\hline Conspecific: Nighttime & 0.399 & 1.491 & 0.264 & 1.515 & 0.130 \\
\hline Mixed: Nighttime & 0.566 & 1.762 & 0.264 & 2.146 & 0.031 \\
\hline
\end{tabular}

The model assumed the baseline hazard function at which snails showed the fleeing response, with a covariate factor of body size, under control condition during daytime phase. log (Shell length) indicates the logarithm of shell length to base 10. Since it took four days to conduct the experiment, the date was treated as a stratification variable in the model. $\mathrm{N}=720$. 
Table 3. Results of four Cox's proportional hazard models to examine the effects of shell length and time phase on the cautious response behavior of the periwinkle, Littorina sitkana, in the four experimental conditions.

\begin{tabular}{|c|c|c|c|c|c|c|}
\hline Condition & Explanatory factor & $\begin{array}{c}\text { Coefficient } \\
\qquad(\beta)\end{array}$ & $\exp (\beta)$ & $\operatorname{SE}(\beta)$ & $Z$ & $P$ \\
\hline \multicolumn{7}{|l|}{ a. Control } \\
\hline & $\log _{10}($ Shell length $)$ & -1.425 & 0.241 & 0.505 & -2.819 & 0.005 \\
\hline & Time phase & & & & & \\
\hline & Morning & 0.073 & 1.075 & 0.194 & 0.374 & 0.708 \\
\hline & Nighttime & -0.479 & 0.620 & 0.196 & -2.441 & 0.015 \\
\hline \multicolumn{7}{|l|}{ b. Crab } \\
\hline & $\log _{10}($ Shell length $)$ & -1.657 & 0.191 & 0.463 & -3.583 & $<0.001$ \\
\hline & Time phase & & & & & \\
\hline & Morning & 0.101 & 1.107 & 0.214 & 0.473 & 0.636 \\
\hline & Nighttime & 0.262 & 1.300 & 0.207 & 1.265 & 0.206 \\
\hline \multicolumn{7}{|l|}{ c. Conspecific } \\
\hline & $\log _{10}$ (Shell length) & -2.224 & 0.108 & 0.463 & -4.807 & $<0.001$ \\
\hline & Time phase & & & & & \\
\hline & Morning & 0.368 & 0.692 & 0.200 & -1.839 & 0.066 \\
\hline & Nighttime & -0.335 & 0.716 & 0.191 & -1.750 & 0.080 \\
\hline \multicolumn{7}{|l|}{ d. Mixed } \\
\hline & $\log _{10}($ Shell length $)$ & -1.651 & 0.192 & 0.489 & -3.378 & $<0.001$ \\
\hline & Time phase & & & & & \\
\hline & Morning & -0.183 & 0.832 & 0.192 & 0.955 & 0.340 \\
\hline & Nighttime & -0.094 & 0.910 & 0.188 & -0.503 & 0.615 \\
\hline
\end{tabular}

The duration of the experiment was 4 days, so in the model the date is treated as a stratification.

Table 4. Model selection table for the fleeing response in Littorina sitkana.

\begin{tabular}{cccccccccc}
\hline Rank & $\begin{array}{c}\text { A) Treat- } \\
\text { ment }\end{array}$ & $\begin{array}{c}\text { B) Time } \\
\text { phase }\end{array}$ & $\begin{array}{c}\text { C) } \log _{10} \\
\text { (Shell length) }\end{array}$ & $\begin{array}{c}\text { Strata } \\
\text { (Date) }\end{array}$ & A : B & A : C & B : C & AIC & $\Delta$ AIC \\
\hline 1 & + & + & -1.420 & + & + & - & - & 3169.0 \\
2 & + & + & -1.352 & + & - & - & - & 3170 \\
3 & + & + & -2.171 & + & + & - & + & 3170 \\
4 & + & + & -2.163 & + & - & - & + & 3171 \\
5 & + & + & -1.470 & + & + & + & - & 3173 \\
\end{tabular}

The best five models are ranked on the basis of AIC. The best model therefore include factors A, B, C and the interaction between A and B (A : B). $\triangle \mathrm{AIC}$ is the difference in AIC between each model and the best model. Symbols as in Table 1; date as explained in Table 3 .

idly during late-evening than at mid-day $(\beta=1.255 \pm$ $0.362)$, there was no significant difference in the occurrence of the fleeing response between morning and midday under the control treatment $(\beta=0.118 \pm 0.395$; Fig. $4 \mathrm{a}$, Table 6a). However, periwinkles moved out of the water more rapidly during the morning than at mid-day under the three experimental treatments (Fig. 4b-d, Table $6 b-d$ ). Larger periwinkles remained longer below the waterline (Tables 5-6).

\section{Discussion}

The laboratory experiments reported here demonstrated that the periwinkle $L$. sitkana responds to chemical cues indicating predation a risk with one of two contrasting anti-predation behaviors. This species is distributed high up within the intertidal zone and even when they were placed in natural seawater under the control treatment, some $L$. sitkana individuals moved above the waterline during the experimental period. These results are consistent with past studies on this species (Behrens Yamada et al. 1989, Rochette \& Dill 2000). Furthermore, L. sitkana individuals detecting chemical cues from a nearby predatory crab reduced their crawling activity, whereas those in the mixed treatment actively crawled to flee from the underwater area. Many periwinkles in both treatments 
finally climbed up the wall of the container above the waterline. However, L. sitkana did not seem to respond to the chemical cue of crushed conspecifics, suggesting that the conspecific cue may not indicate predation risk in itself in the population of $L$. sitkana used in this study. However, periwinkles may receive this chemical cue as an indicator of a high level of predation risk when they sense it in addition to the risk from a chemical cue indicating a nearby predatory crab, particularly since in the experiments reported here the crabs were observed to forage very actively on the periwinkles that had been crushed during the preparation of seawater containing the mixed chemical cues.

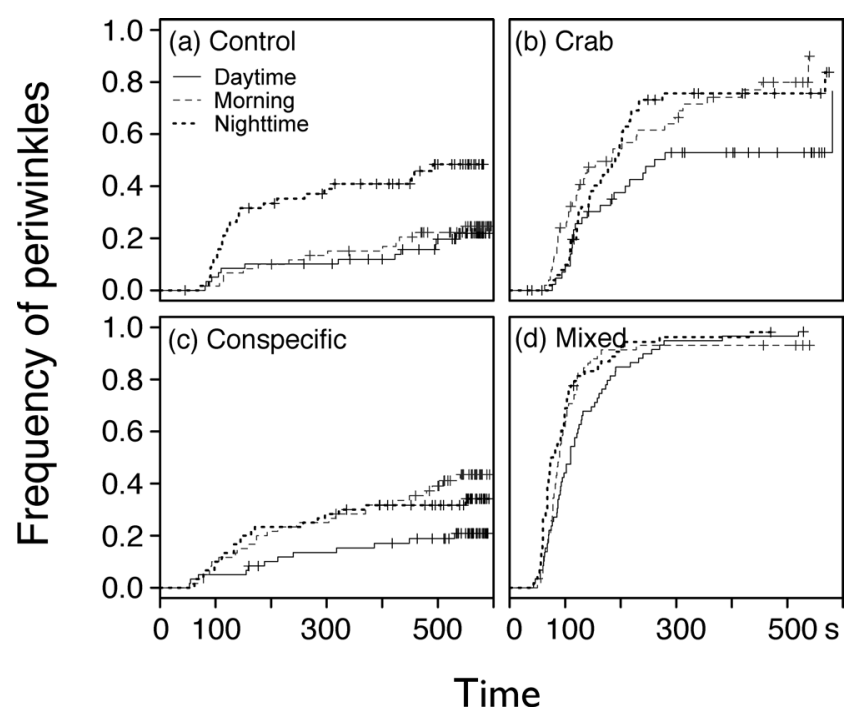

Fig. 4. Comparison of the proportion of Littorina sitkana individuals showing fleeing response for each of four types of chemical cue at different times of day. (Crosses as explained in caption to Fig. 3).
This suggests that $L$. sitkana assesses the level of predation risk and decides which behavioral strategy to adopt from the two contrasting anti-predation responses. Mach \& Bourdeau (2011) demonstrated in the whelk, Nucella ostrina, that cues from injured conspecifics induces rapid initiation of active fleeing while cues from predatory crabs induces withdrawal into the shell. Many gastropod species may exhibit a range of antipredation behaviors and choose one based on the information conveyed by the detected risk cue (Turner et al. 1999, Ichinose 2002).

Body size also affected the anti-predation behavior of $L$. sitkana in the present study, with larger periwinkles remaining within the circle and beneath the water level longer than smaller individuals. Anti-predation traits can be classified as constitutive and induced (Zangerl \& Rutledge 1996). Constitutive morphological traits are always expressed, such as the shell of gastropods, whereas induced traits, including anti-predation behaviors, are expressed after a predation threat is detected. As both types of antipredation traits entail costs, a trade-off between constitutive and induced traits should affect the anti-predation response of animals (Kurihara 2003). High effectiveness in constitutive traits should be matched by low performance in induced traits, and vice-versa (Zangerl \& Rutledge 1996). Larger L. sitkana may have stronger shells and therefore stronger constitutive defenses against predation by $H$. sanguineus. However, Rochette \& Dill (2000) showed that large individuals of $L$. sitkana are more vulnerable than small ones to the predatory crab Cancer productus, and that larger periwinkles display clearer anti-predation behaviors. In this respect, fleeing might be more hazardous for larger individuals if the predators use visual cues to detect their food (Palma \& Steneck 2001). Large $L$. sitkana individuals may perform a cautious response due to higher risk of predation than small individuals, although

Table 5. Results of the best model to explain the fleeing response behavior of the periwinkle, Littorina sitkana.

\begin{tabular}{|c|c|c|c|c|c|}
\hline Explanatory factor & Coefficient $(\beta)$ & $\exp (\beta)$ & $\operatorname{SE}(\beta)$ & $Z$ & $P$ \\
\hline \multicolumn{6}{|l|}{ Treatment } \\
\hline Crab & 1.284 & 3.613 & 0.358 & 3.590 & $<0.001$ \\
\hline Conspecific & -0.037 & 0.964 & 0.409 & -0.091 & 0.928 \\
\hline Mixed & 2.634 & 13.925 & 0.322 & 8.168 & $<0.001$ \\
\hline $\log _{10}$ (Shell length) & -1.420 & 0.242 & 0.314 & -4.517 & $<0.001$ \\
\hline \multicolumn{6}{|l|}{ Time phase } \\
\hline Morning & 0.133 & 1.143 & 0.394 & 0.338 & 0.735 \\
\hline Nighttime & 1.280 & 3.595 & 0.352 & 3.634 & $<0.001$ \\
\hline \multicolumn{6}{|l|}{ Treatment: Time phase } \\
\hline Crab: Morning & 0.578 & 1.783 & 0.476 & 1.214 & 0.225 \\
\hline Conspecific: Morning & 0.760 & 2.139 & 0.529 & 1.438 & 0.150 \\
\hline Mixed: Morning & 0.245 & 1.278 & 0.440 & 0.558 & 0.577 \\
\hline Crab: Nighttime & -0.592 & 0.553 & 0.440 & -1.343 & 0.179 \\
\hline Conspecific: Nighttime & -0.672 & 0.510 & 0.507 & -1.325 & 0.185 \\
\hline Mixed: Nighttime & -0.523 & 0.593 & 0.401 & -1.302 & 0.193 \\
\hline
\end{tabular}

Cox's proportional hazard model was applied, assuming the baseline hazard function at which snails showed the fleeing response, with a covariate factor of body size, under control condition during daylight. Date as explained in Table 3. N=720. 
Table 6. Results of four Cox's proportional hazard models to examine the effects of shell length and time phase on the fleeing response behavior of the periwinkle, Littorina sitkana, in the four experimental conditions.

\begin{tabular}{|c|c|c|c|c|c|c|}
\hline Condition & Explanatory factor & $\begin{array}{c}\text { Coefficient } \\
(\beta)\end{array}$ & $\exp (\beta)$ & $\operatorname{SE}(\beta)$ & $Z$ & $P$ \\
\hline \multicolumn{7}{|l|}{ a. Control } \\
\hline & $\log _{10}($ Shell length $)$ & -1.193 & 0.303 & 0.920 & -1.298 & 0.194 \\
\hline & Time phase & & & & & \\
\hline & Morning & 0.118 & 1.125 & 0.395 & 0.299 & 0.765 \\
\hline & Nighttime & 1.255 & 3.508 & 0.362 & 3,471 & $<0.001$ \\
\hline \multicolumn{7}{|l|}{ b. Crab } \\
\hline & $\log _{10}($ Shell length $)$ & -1.316 & 0.268 & 0.556 & -2.368 & 0.018 \\
\hline & Time phase & & & & & \\
\hline & Morning & 0.827 & 2.285 & 0.279 & 2.960 & 0.003 \\
\hline & Nighttime & 0.780 & 2.181 & 0.286 & 2.725 & 0.006 \\
\hline \multicolumn{7}{|l|}{ c. Conspecific } \\
\hline & $\log _{10}$ (Shell length) & -2.533 & 0.079 & 0.810 & -3.129 & 0.002 \\
\hline & Time phase & & & & & \\
\hline & Morning & 0.896 & 2.449 & 0.355 & 2.522 & 0.012 \\
\hline & Nighttime & 0.577 & 1.781 & 0.367 & 1.572 & 0.116 \\
\hline \multicolumn{7}{|l|}{ d. Mixed } \\
\hline & $\log _{10}$ (Shell length) & -1.175 & 0.309 & 0.518 & -2.266 & 0.023 \\
\hline & Time phase & & & & & \\
\hline & Morning & 0.428 & 1.534 & 0.207 & 2.070 & 0.038 \\
\hline & Nighttime & 0.749 & 2.114 & 0.211 & 3.545 & $<0.001$ \\
\hline
\end{tabular}

Date as explained in footnote to Table 3.

further studies are needed to examine whether or not the crab $H$. sanguineus uses visual cues to find the periwinkle L. sitkana.

Time of day also affected the anti-predation response of L. sitkana, crawling out of the water faster in the late-evening than at mid-day, a pattern apparently consistent with that of other gastropods (Kosin 1964, Rogers 1968, Phillips 1975). For example, two species of limpet showed greater negative geotaxis in dark conditions than in light conditions under the influence of a chemical cue from predatory starfish (Phillips 1975). Diurnal variation in predation risk, which may be due to the diurnal rhythm in the behavior of predators, may cause such patterns (Jacobsen \& Stabell 1999). However, in the present study, L. sitkana did not show diurnal differences in both the cautious and fleeing responses under the mixed treatment. Since crabs actively foraged on the crushed conspecifics under the mixed treatment, the periwinkles may associate the mixed cue treatment with a high predation risk. In this situation, they would show a very short cautious response and quickly move out of the water, irrespective of the time of day.

\section{Acknowledgements}

We thank Dr. Osamu Kishida, Dr. Takashi Oba and other members of Laboratory of Marine Biology, Graduate School of Fisheries Science, Hokkaido University for their constructive comments throughout this study. Staff of Usujiri Fisheries Station, Field Science Center for Northern Biosphere, Hokkaido University provided a good facility for conducting our experiment. We are also grateful to the anonymous reviewers who provided some useful statistical comments.

\section{References}

Behrens Yamada S, Navarrete SA, Needham C (1998) Predation induced changes in behavior and growth rate in three populations of the intertidal snail, Littorina sitkana (Phillippi). J Exp Mar Biol Ecol 220: 213-226.

Chivers DP, Wisenden BD, Smith JF (1996) Damselfly larvae learn to recognize predators from chemical cues in the predator's diet. Anim Behav 52: 315-320.

Crowl TA, Covich AP (1990) Predator-induced life-history shifts in a freshwater snail. Science 247: 949-951.

Gristina M, Sinopoli M, Fiorentino F, Garofalo G, Badalamenti F (2011) Shelter selection of the spiny lobster Palinurus elephas under different levels of Octopus vulgaris predation threat. Mar Biol 158: 1331-1337.

Hazlett BA (1994) Alarm responses in the crayfish Orconectes virilis and Orconectes propinquus. J Chem Ecol 20: 15251535.

Hazlett BA, McLay C (2000) Contingencies in the behavior of the crab Heterozius rotundifrons. Anim Behav 59: 965-974.

Higuchi M, Koyano T, Ito A, Wada S (2004) Predator avoidance 
of the conch snail Strombus luhuanus. Aquacul Sci 52: 251258.

Ichinose K (2002) Influence of age and body size on alarm responses in freshwater snail Pomacea canaliculata. J Chem Ecol 28: 2017-2028.

Iwami T, Kishida O, Nishimura K (2007) Direct and indirect induction of a compensatory phenotype that alleviates the costs of an inducible defense. PLoS ONE 2: e1084.

Jacobsen HP, Stabell OB (1999) Predator-induced alarm responses in the common periwinkle, Littorina littorea: dependence on season, light conditions, and chemical labelling of predators. Mar Biol 134: 551-557.

Jones KMM, Boulding EG (1999) State-dependent habitat selection by an intertidal snail: the costs of selecting a physically stressful microhabitat. J Exp Mar Biol Ecol 242: 149-177.

Kishida O, Mizuta Y, Nishimura K (2006) Reciprocal phenotypic plasticity in a predator-prey interaction between larval amphibians. Ecology 87: 1599-1604.

Kosin DF (1964) Light responses of Tegula funebralis (Mollusca: Gastropoda). Veliger 6(Suppl): 46-50.

Kurihara T (2003) Adaptations of subtropical venus clams to predation and desiccation: endurance of Gafrarium tumidum and avoidance of Ruditapes variegatus. Mar Biol 143: 1117-1125.

Lehtiniemi M (2005) Swim or hide: predator cues cause species specific reactions in young fish larvae. J Fish Biol 66: 12851299.

Lima SL, Dill LM (1990) Behavioral decisions made under the risk of predation: A review and prospectus. Can J Zool 68: 619-640.

Lively CM (1986) Predator-induced shell dimorphism in the acorn barnacle Chthamalus anisopoma. Evolution 40: 232 242.

Mach ME, Bourdeau PE (2011) To flee or not to flee? Risk assessment by a marine snail in multiple cue environments. J Exp Mar Biol Ecol 409: 166-171.

Martín J, López P (2000) Costs of refuge use affect escape decisions of Iberian rock lizards Lacerta monticola. Ethology 106: 483-492.

Martín J, Marcos I, López P (2005) When to come out from your own shell: risk-sensitive hiding decisions in terrapins. Behav Ecol Sociobiol 57: 405-411.

Mathis A, Hoback WW (1997) The influence of chemical stimuli from predators on precopulatory pairing by the amphipod, Gammarus pseudolimnaeus. Ethology 103: 33-40.

Mima A, Wada S, Goshima S (2003) Antipredator defence of the hermit crab Pagurus filholi induced by predatory crabs. Oikos 102: 104-110.

Palma AT, Steneck RS (2001) Does variable coloration in juve- nile marine crabs reduce risk of visual predation? Ecology 82 : 2961-2967.

Phillips DW (1975) Distance chemoreception-triggered avoidance behaviour of the limpets Acmaea (Collisella) limatula and Acmaea (Notoacmea) scutum to the predatory starfish Pisaster ochraceus. J exp Zool 191: 199-210.

R Development Core Team (2011) R: a language and environment for statistical computing [Internet]. Vienna (Austria): R Foundation for Statistical Computing. Available from: http:// www.R-project.org

Reaney LT (2007) Foraging and mating opportunities influence refuge use in the fiddler crab, Uca mjoebergi. Anim Behav 73: 711-716.

Rochette R, Dill LM (2000) Mortality, behavior and the effects of predators on the intertidal distribution of littorinid gastropods. J Exp Mar Biol Ecol 253: 165-191.

Rogers DA (1968) The effect of light and tide on movements of the limpet Acmaea scutum. Veliger 11(Suppl): 20-25.

Sakamoto R, Ito A, Wada S (2006) Combined effect of risk type and activity rhythm on anti-predator response of the shore crab Gaetice depressus (Crustacea: Grapsidae). J Mar Biol Assoc UK 86: 1401-1405.

Selden R, Johnson AS, Ellers O (2009) Waterborne cues from crabs induce thicker skeletons, smaller gonads and size-specific changes in growth rate in sea urchins. Mar Biol 156: 1057-1071.

Skajaa K, Fernö A, Løkkeborg S, Haugland EK (1998) Basic movement pattern and chemo-oriented search towards baited pots in edible crab (Cancer pagurus L.). Hydrobiologia 371/372: 143-153.

Turner AM, Fetterolf SA, Bernot RJ (1999) Predator identity and consumer behavior: differential effects of fish and crayfish on the habitat use of a freshwater snail. Oecologia 118: 242-247.

Vaughn D (2010) Why run and hide when you can divide? Evidence for larval cloning and reduced larval size as an adaptive inducible defense. Mar Biol 157: 1301-1312.

Wasson K, Lyon BE (2005) Flight or fight: flexible antipredatory strategies in porcelain crabs. Behav Ecol 16: 1037-1041.

Wellborn GA (2002) Trade-off between competitive ability and antipredator adaptation in a freshwater amphipod species complex. Ecology 83: 129-136.

Yoshimura K, Motokawa T (2010) Bilaterality in the regular sea urchin Anthocidaris crassispina is related to efficient defense not to efficient locomotion. Mar Biol 157: 2475-2488.

Zangerl AR, Rutledge CE (1996) The probability of attack and patterns of constitutive and induced defense: a test of optimal defense theory. Am Nat 147: 599-608. 